\title{
Aclidinium inhibits cigarette smoke-induced lung fibroblast-to-myofibroblast transition
}

\author{
Javier Milara*,\#, $\uparrow_{, * *}$, Adela Serrano*,**, Teresa Peiró*, Enrique Artigues ${ }^{+}$, \\ Amadeu Gavaldà ${ }^{\S}$, Montse Miralpeix ${ }^{\S}$, Esteban J. Morcillo ${ }^{\#, f}$ and Julio Cortijo*,\#,f
}

ABSTRACT: Cigarette smoking contributes to lung remodelling in chronic obstructive pulmonary disease (COPD). As part of this remodelling, peribronchiolar fibrosis is observed in the small airways of COPD patients and contributes to airway obstruction. Fibroblast-to-myofibroblast transition is a key step in peribronchiolar fibrosis formation.

This in vitro study examined the effect of cigarette smoke on bronchial fibroblast-tomyofibroblast transition, and whether aclidinium bromide inhibits this process. Human bronchial fibroblasts were incubated with aclidinium bromide $\left(10^{-9}-10^{-7} \mathrm{M}\right)$ and exposed to cigarette smoke extract. Collagen type I and $\alpha$-smooth muscle actin ( $\alpha$-SMA) expression were measured by realtime PCR and Western blotting, as myofibroblast markers. Intracellular reactive oxygen species, cyclic AMP (CAMP), extracellular signal-regulated kinase (ERK)1/2 and choline acetyltransferase were measured as intracellular signalling mediators.

Cigarette smoke-induced collagen type I and $\alpha$-SMA was mediated by the production of reactive oxygen species, the depletion of intracellular CAMP and the increase of ERK1/2 phosphorylation and choline acetyltransferase. These effects could be reversed by treatment with the anticholinergic aclidinium bromide, by silencing the mRNA of muscarinic receptors M1, M2 or M3, or by the depletion of extracellular acetylcholine by treatment with acetylcholinesterase.

A non-neuronal cholinergic system is implicated in cigarette smoke-induced bronchial fibroblast-to-myofibroblast transition, which is inhibited by aclidinium bromide.

KEYWORDS: Anticholinergic, chronic obstructive pulmonary disease, cigarette smoke, nonneuronal cholinergic system

hronic obstructive pulmonary disease (COPD) is characterised by airflow limitation that is progressive and not fully reversible. Cigarette smoking is the main risk factor for COPD and contributes to structural changes in airways during COPD progression [1]. Structural changes in COPD patients are characterised by loss of alveolar wall (emphysema), vascular remodelling with pulmonary hypertension, mucus hypersecretion or peribronchiolar fibrosis [1]. As part of fibrotic alterations in COPD, structural changes are seen primarily in small airways. The severity of the disease appears to correlate with thickening of the walls of small airways caused by fibrosis and infiltration of inflammatory cells, which contributes to airflow obstruction [2]. Accumulation and persistence of myofibroblasts is believed to contribute to the development of small airway fibrosis. In this respect, under chronic inflammatory conditions, resident lung fibroblasts are activated and transformed into a more contractile, proliferative and secretory-active myofibroblast phenotype, characterised by increased expression of extracellular matrix components and $\alpha$-smooth muscle actin $(\alpha-\mathrm{SMA})$, which contributes to the increase of lung remodelling progression and airway bronchoconstrictor responsiveness [3].

Parasympathetic activity is increased in the airways of COPD patients and is the basis for the use of anti-cholinergic therapy [4]. Anti-cholinergics constitute a particularly important bronchodilator therapy in COPD and certain forms of asthma [5]. Furthermore, in animal models, anticholinergics have shown potential anti-inflammatory and antiremodelling effects [6], which may be of additional value to their classical bronchodilator effects.

Recently, it has been proposed that acetylcholine in the airways may be released by non-neuronal cell types, such as airway epithelial cells and lung fibroblasts. Therefore, a dysfunction of a non-neuronal cholinergic system may contribute

\section{AFFILIATIONS}

${ }^{*}$ Research Unit, University General Hospital Consortium, Valencia,

${ }^{*}$ CIBERES, Health Institute Carlos III, Valencia,

"Dept of Biotechnology, Universidad Politécnica de Valencia, Valencia,

${ }^{+}$Dept of Surgery, General University Hospital of Valencia, Valencia, ${ }^{f}$ Dept of Pharmacology, Faculty of Medicine, University of Valencia, Valencia, and

${ }^{\S}$ Almirall, R\&D Centre, Barcelona, Spain

**Both authors contributed equally to this work.

CORRESPONDENCE

J. Milara

Fundación de Investigación,

Consorcio

Hospital General Universitario

Avenida tres cruces s/n

E-46014 Valencia

Spain

E-mail: xmilara@hotmail.com

Received:

Jan 282012

Accepted after revision:

Aug 272012

First published online:

Sept 272012 
to the pathophysiology of asthma and COPD [7]. It has been shown that anticholinergic treatment inhibits cigarette smokeinduced mucin hypersecretion in human bronchial epithelial cells [8], as well as cigarette smoke-induced lung fibroblast proliferation [9]. Furthermore, choline acetyltransferase (ChAT), the intracellular enzyme responsible for acetylcholine production, is upregulated in both lung fibroblasts from COPD patients and fibroblasts stimulated with cigarette smoke [9]. However, no data exist concerning the role of cigarette smoke on fibroblast to myofibroblast transition, as well as the potential inhibitory effect of anticholinergics.

Aclidinium bromide is a novel, inhaled, long-acting muscarinic antagonist compound with low systemic activity that has completed phase III clinical development for COPD treatment [10]. In preclinical studies, aclidinium bromide demonstrated potent muscarinic-antagonist activity, comparable to that of ipratropium bromide and tiotropium bromide, and a long duration of action [11]. In clinical trials, aclidinium bromide has provided sustained bronchodilation, similar to that observed with tiotropium bromide, a good safety profile and low incidence of anticholinergic adverse events [10].

In this study, we investigated the role of aclidinium bromide on the increase of the myofibroblast markers collagen type I and $\alpha$-SMA elicited by chronic cigarette smoke exposure in human bronchial fibroblasts, as well as the intracellular pathways involved in this process.

\section{METHODS}

See the online supplementary material for further details of the methods used.

\section{Isolation and cultivation of human fibroblasts}

Human bronchial fibroblasts were obtained from patients undergoing surgery for lung carcinoma who gave informed consent, as previously described [12]. Cultivation and characterization of fibroblasts were performed as described elsewhere [12]. The protocol for obtaining human tissue was approved by the local ethical review board for human studies (General Hospital of Valencia, Valencia, Spain). See the online supplementary material for details.

\section{Preparation of cigarette smoke extract and incubations}

Cigarette smoke extract (CSE) solutions were prepared as previously described [13]. Briefly, the smoke of a research cigarette (2R4F; Tobacco Health Research, University of Kentucky, Lexington, KY, USA) was bubbled into a flask containing $25 \mathrm{~mL}$ pre-warmed $\left(37^{\circ} \mathrm{C}\right)$ Dulbecco's Modified Eagle's Medium. The resulting solution was defined as CSE at $100 \%$. CSE at $10 \%$ reportedly corresponds to the exposure associated with smoking approximately 1-2 packs per day [14]. Before stimulation, subconfluent cell monolayers were deprived of serum for $24 \mathrm{~h}$. Human bronchial fibroblasts were stimulated with CSE (0-10\%) for different periods of time (0$72 \mathrm{~h}$ ), replacing the culture medium and stimulus every $24 \mathrm{~h}$. Different drug modulators were added $30 \mathrm{~min}$ before the stimulus. See the online supplementary material for details.

\section{Real-time RT-PCR}

Total RNA was isolated from cultured human bronchial fibroblasts by using TriPure ${ }^{\circledR}$ (Roche, Indianapolis, IN, USA), and reverse-transcribed and amplified with specific primers. Relative quantification of these different transcripts was determined with the $2^{-\Delta \Delta C t}$ method using glyceraldehyde phosphate dehydrogenase as an endogenous control (Applied Biosystems, Foster City, CA, USA) and normalised to the control group. See the online supplementary material for details.

\section{Transfection of small interfering RNAs}

Small interfering RNA (siRNA) for M1, M2 and M3 receptors and the scrambled siRNA control were purchased from Ambion (Cambridge, UK). The transfection reagent used was Lipofectamine 2000 (Invitrogen, Paisley, UK) at a final concentration of $2 \mu \mathrm{L} \cdot \mathrm{mL}^{-1}$. See the online supplementary material for details.

\section{Western blotting}

Western blot analysis was used to detect changes in collagen type I (138 kDa), $\alpha$-SMA, phosphorylate extracellular signalregulated kinase (ERK)1/2 (42-44 kDa), M1 (52 kDa), M2 (70 kDa), M3 (75 kDa), p67 ${ }^{\text {phox }}(67 \mathrm{kDa}), \mathrm{NADPH}$ oxidase $(\mathrm{NOX}) 4(67 \mathrm{kDa})$ and ChAT $(65 \mathrm{kDa})$ in bronchial fibroblast lysates. See the online supplementary materials for details of Western blot analyses and antibodies used.

\section{Dichlorodihydrofluorescein fluorescence measurement of reactive oxygen species}

$2^{\prime}, 7^{\prime}$-dichlorodihydrofluorescein diacetate $\left(\mathrm{H}_{2} \mathrm{DCF}-\mathrm{DA}\right.$; Molecular Probes, Nottingham UK) was used to monitor the intracellular reactive oxygen species (ROS) in bronchial fibroblasts. See the online supplementary material for details.

\section{Cyclic AMP assay}

Human lung fibroblasts were cultured in 96-well plates to $\sim 95 \%$ confluence. Following different treatments, cells were lysed and intracellular cyclic AMP (cAMP) content was determined with the cAMP Biotrak enzyme immunoassay according to manufacturer's instructions (Amersham, Cambridge, UK). Results were expressed as femtomoles per well.

\section{Analysis of results}

Data presented as mean \pm SEM of $n$ experiments. Statistical analysis of data was performed by ANOVA followed by the Bonferroni test (GraphPad Software Inc., San Diego, CA, USA). Significance was accepted when p-values were $<0.05$.

\section{RESULTS}

Aclidinium bromide attenuates CSE-induced myofibroblast markers in human bronchial fibroblast cultures

CSE, at $2.5 \%$ concentration, upregulated collagen type I and $\alpha$ SMA in a time-dependent manner, reaching peak values following $48 \mathrm{~h}$ of CSE 2.5\% exposure (fig. $1 \mathrm{a}$ and b). Furthermore, CSE dose-dependently increased collagen type I and $\alpha$-SMA mRNA and protein expression, reaching statistical significance at $2.5 \%$ concentration following $48 \mathrm{~h}$ of exposure (fig. 1c-f). Thus, we selected this CSE concentration to evaluate myofibroblast marker expression in future experiments.

In other experiments, aclidinium bromide was added $30 \mathrm{~min}$ before CSE $2.5 \%$ and further incubated for $48 \mathrm{~h}$. Aclidinium bromide dose-dependently reduced the CSE-induced collagen type I and $\alpha$-SMA mRNA and protein expression, reaching a maximal inhibitory value at $10^{-7} \mathrm{M}$ (fig. $2 \mathrm{a}-\mathrm{c}$ ). Similar results were observed for atropine, reaching significant inhibition of 

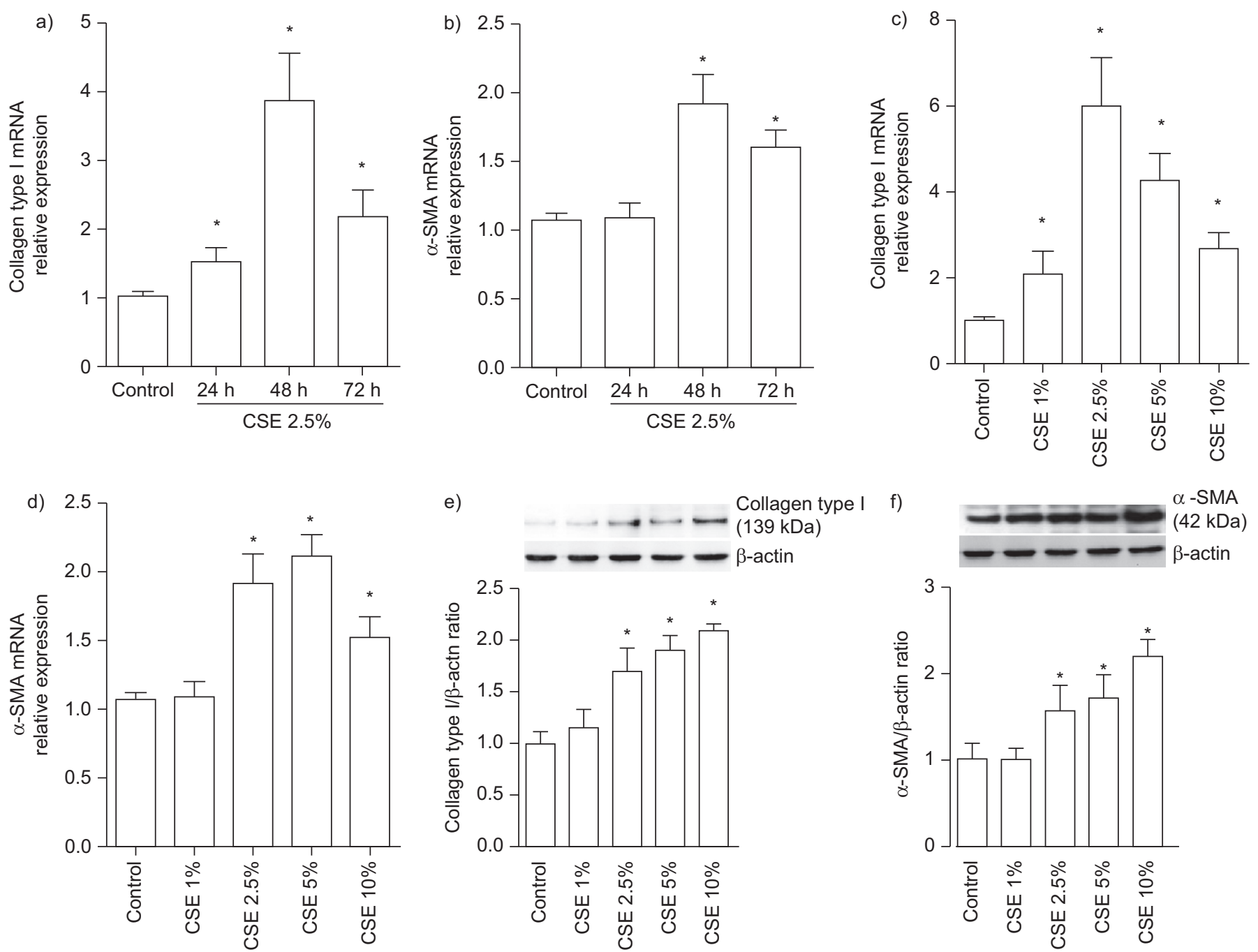

FIGURE 1. Cigarette smoke extract (CSE) time and dose-dependently increased collagen type I and $\alpha$-smooth muscle actin ( $\alpha$-SMA) in human bronchial fibroblasts Human lung fibroblasts were stimulated with CSE $a, b)$ at the indicated times or $\mathrm{c}-\mathrm{f}$ ) for $48 \mathrm{~h}$ at the indicated concentrations. a-d) After incubation, the RNA was extracted and subjected to RT-PCR with collagen type I- and $\alpha$-SMA-specific primers and probes. e, f) After incubation, total protein was extracted and Western blots were performed with specific antibodies for collagen type I and $\alpha$-SMA. e, f) Data represent densitometries of three different Western blots. Each bar represents the mean \pm SEM of a-d) four or e, f) three independent experiments. a-f) One-way repeated-measures ANOVA $p<0.001$. *: $p<0.05$ with post hoc Bonferroni test compared with solvent controls.

both myofibroblast markers at $1 \mu \mathrm{M}$, suggesting the participation of a cholinergic pathway in this process (fig. $2 d-f$ ). Neither aclidinium nor atropine by themselves showed any effect on myofibroblast markers (figs S1 and S2).

\section{Aclidinium bromide reduces intracellular ROS elevated by CSE in human bronchial fibroblasts}

In our experiments on human primary lung fibroblasts, CSE (2.5-10\%) dose-dependently increased intracellular ROS generation, reaching a significant value after $2 \mathrm{~h}$ of stimulation that was sustained for $24 \mathrm{~h}$ (fig. 3a). Pretreatment of bronchial fibroblasts with aclidinium bromide dose-dependently reduced the CSE-induced ROS by nearly $50 \%$ at $10^{-7} \mathrm{M}$ after $24 \mathrm{~h}$ of CSE $2.5 \%$ stimulation (fig. 3b-e). In parallel experiments, quenching of ROS by apocynin $(100 \mu \mathrm{M})$ or $N$-acetyl-Lcysteine (NAC) $(1 \mathrm{mM})$, as well as increasing cAMP with its analogue dibutyryl-cAMP (dbcAMP), suppressed CSE $2.5 \%$ triggered intracellular ROS production (fig. 3e).
The NADPH oxidase complex is comprised of several cytosolic and plasma membrane subunits [15]. Among the subunits analysed, we found that the cytosolic subunit $\mathrm{p} 67^{\text {phox }}$ and the plasma membrane subunit NOX4 were the most highly expressed in bronchial fibroblasts under basal conditions (fig. 4a). Following 24-h exposure, CSE 2.5\% upregulated both mRNA transcripts and protein expression of $\mathrm{p}^{6} 7^{\text {phox }}$ and NOX4, which were dose-dependently reverted to near control values by exposure to aclidinium bromide $10^{-7} \mathrm{M}$ (fig. $4 \mathrm{~b}-\mathrm{d}$ ).

\section{CSE activation of non-neuronal cholinergic system is inhibited by aclidinium bromide}

Previous reports have indicated that CSE activates a nonneuronal cholinergic system in lung fibroblasts, but the mechanism remains unclear. Since ChAT is the intracellular enzyme responsible for acetylcholine synthesis, we next explored the effect of CSE on ChAT expression. In this regard, CSE 2.5\% increased ChAT expression, which was dose-dependently 

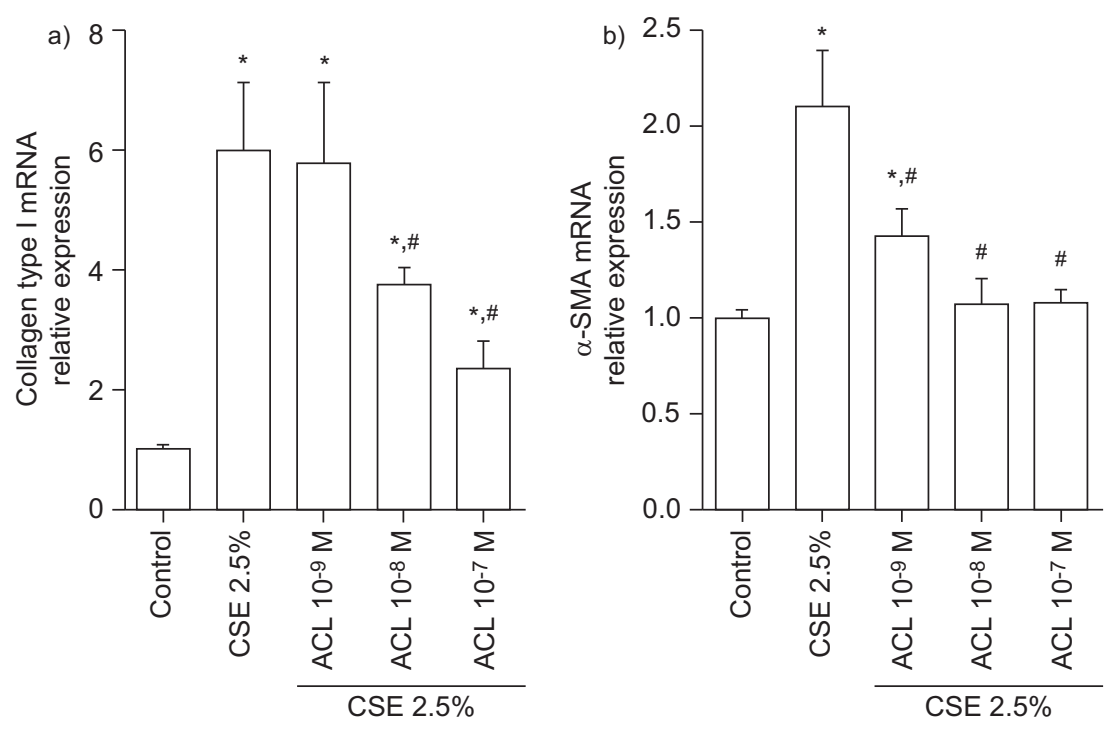

c)
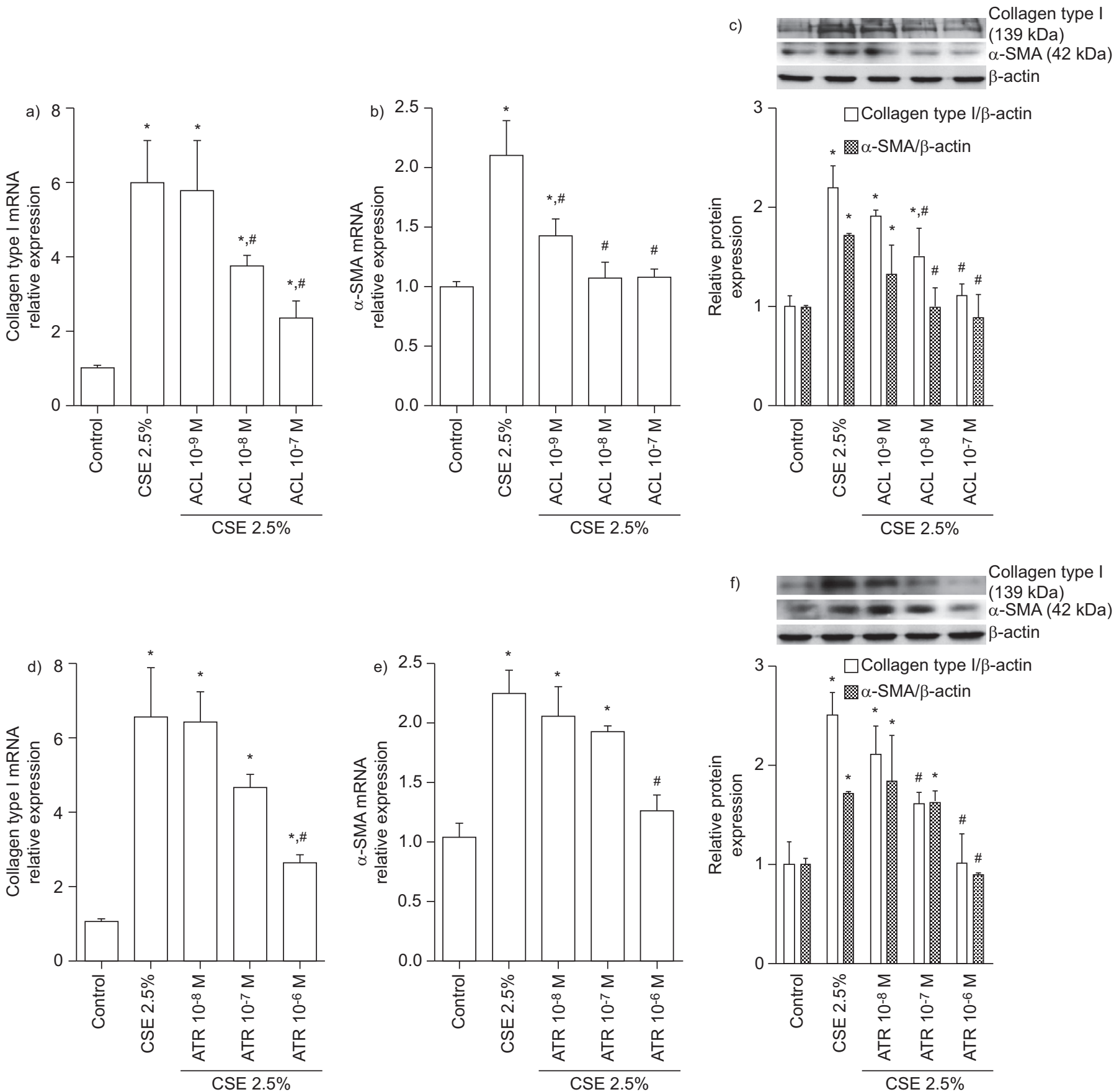

FIGURE 2. Aclidinium bromide (ACL) dose-dependently reduced the cigarette smoke extract (CSE)-induced collagen type I and $\alpha$-smooth muscle actin ( $\alpha$-SMA) in human bronchial fibroblasts. Human lung fibroblasts were stimulated with CSE for $48 \mathrm{~h}$. ACL or atropine (ATR) were added to the medium at the indicated concentrations 30 min before CSE. a, b, d, e) Total RNA and c, f) protein were extracted after the incubation period. RT-PCR for a, d) collagen type I or b, e) $\alpha$-SMA. c, f) Densitometry of collagen type I or $\alpha$-SMA protein expression relative to $\beta$-actin and normalised to solvent controls. Representative Western blots of collagen type I and $\alpha$-SMA are shown. Each graph represents the mean \pm SEM of three experiments for Western blots and four independent experiments for RNA experiments. a-c) One-way repeated-measures ANOVA $p<0.001$. *: $p<0.05$ with post hoc Bonferroni test compared with solvent controls; ${ }^{\#}: p<0.05$ with post hoc Bonferroni test compared with stimulus.

inhibited by aclidinium bromide and by the antioxidants apocynin $100 \mu \mathrm{M}$ and NAC $1 \mathrm{mM}$ (fig. 5a).

Intracellular levels of cAMP and phosphorylation of ERK1/2 have been related to the activation of human lung fibroblasts $[12,16]$. In this work, we observed that CSE 2.5\% reduced intracellular cAMP levels and increased the ERK1/2 phosphorylation following $24 \mathrm{~h}$ of exposure (fig. 5b-d). Aclidinium bromide pretreatment dosedependently reduced the cAMP downregulation as well as reducing the increase of ERK1/2 phosphorylation (fig. 5b and c). Furthermore, the antioxidant treatment with apocynin $100 \mu \mathrm{M}$ or NAC $1 \mathrm{mM}$ also reversed the CSE-induced cAMP downregulation 

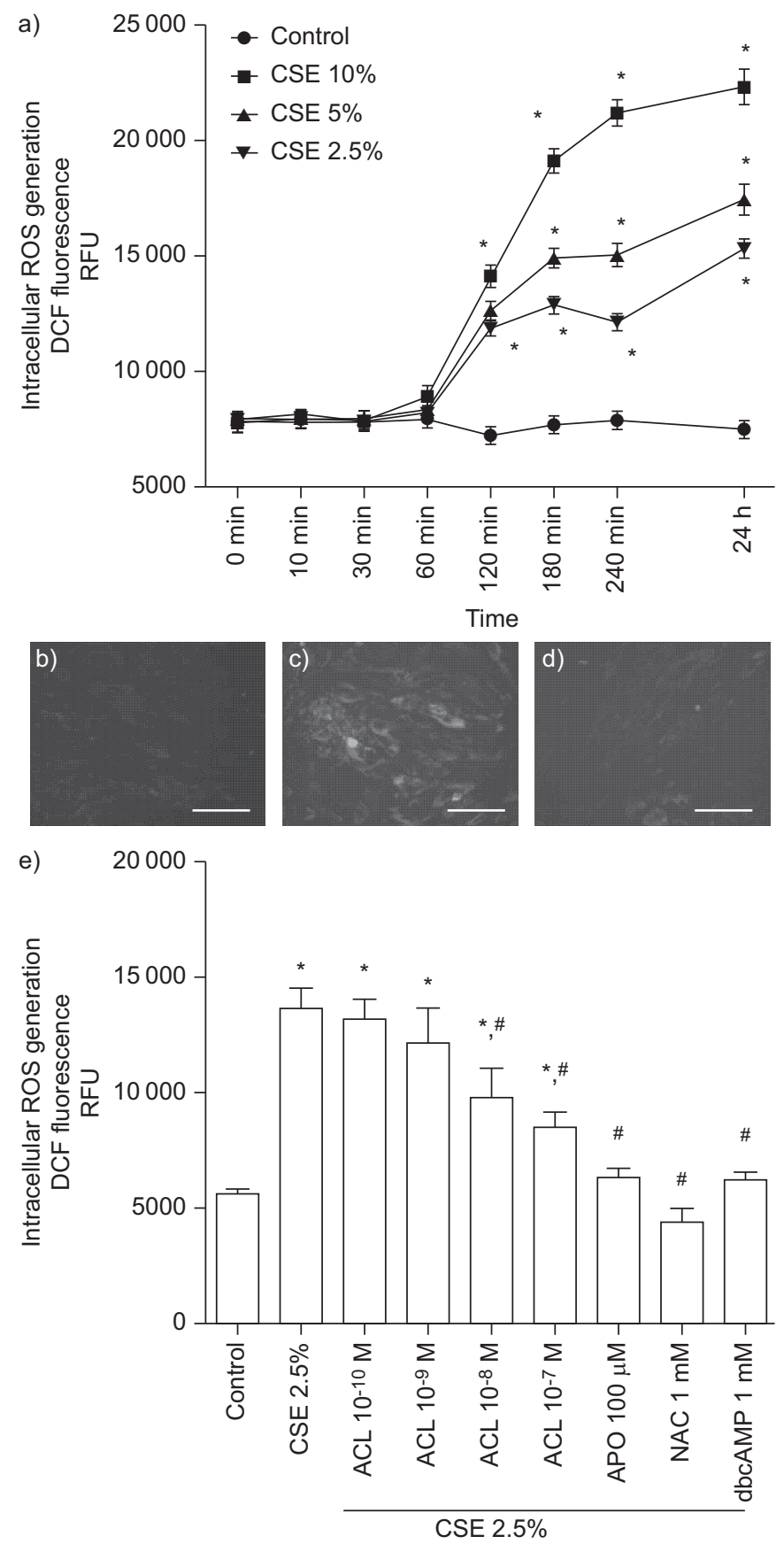

FIGURE 3. Aclidinium bromide (ACL) mitigated cigarette smoke extract (CSE)induced intracellular reactive oxygen species (ROS) generation in human bronchial fibroblasts. a) Human bronchial fibroblasts were loaded with 2',7'-dichlorodihydrofluorescein diacetate $\left(\mathrm{H}_{2} \mathrm{DCF}-\mathrm{DA}\right) 30 \mathrm{~min}$ before CSE stimulation. CSE dose- and time-dependently increased intracellular ROS in human bronchial fibroblasts. b-e) Human bronchial fibroblasts were loaded with $\mathrm{H}_{2}$ DCF-DA in the presence or absence of ACL $\left(10^{-10}-10^{-7} \mathrm{M}\right)$, apocynin (APO; $\left.100 \mu \mathrm{M}\right), \mathrm{N}$-acetyl-L-cysteine (NAC; $1 \mathrm{mM}$ ), dibutyryl cyclic AMP (dbcAMP; $1 \mathrm{mM}$ ) or vehicle for 30 min. Excess $\mathrm{H}_{2} \mathrm{DCF}-$ DA was removed by washing with PBS. ACL, APO, NAC, dbcAMP or vehicle were appropriately replenished before cells were exposed to CSE. b-d) Representative dichlorodihydrofluorescein (DCF) fluorescence images following $24 \mathrm{~h}$ of basal or CSE 2.5\% stimulation in presence or absence of ACL: b) control; c) CSE; d) $10^{-7} \mathrm{M}$ $\mathrm{ACL}$ plus CSE. Scale bars $=25 \mu \mathrm{m}$. e) $\mathrm{ACL}$ dose-dependently attenuated the CSE $2.5 \%$-induced intracellular ROS after $24 \mathrm{~h}$ of stimulation. Similar results were found for APO, NAC and dbcAMP. Results represent the mean \pm SEM of three independent experiments. RFU: relative fluorescence units. a, e) One-way repeated-measures ANOVA $p<0.001 .{ }^{*}: p<0.05$ with post hoc Bonferroni test compared with solvent controls; ${ }^{*}: \mathrm{p}<0.05$ with post hoc Bonferroni test compared with stimulus.

and ERK1/2 phosphorylation (fig. $5 \mathrm{~b}$ and d). Since CSE may activate a non-neuronal cholinergic system, we added the enzyme acetylcholinesterase $(\mathrm{AChE})\left(10 \mathrm{U} \cdot \mathrm{mL}^{+1}\right)$ to remove any extracellular acetylcholine during the 24 -h period of CSE $2.5 \%$ stimulation. AChE partially reversed cAMP downregulation and ERK1/2 phosphorylation induced by CSE (fig. $5 b$ and d).

The antioxidants NAC $1 \mathrm{mM}$ and apocynin $100 \mu \mathrm{M}$, as well as the cAMP analogue dbcAMP and the ERK1/2 inhibitor PD98059 $10 \mu \mathrm{M}$, partially suppressed the CSE-induced collagen type I and $\alpha$-SMA mRNA and protein expression (fig. $6 \mathrm{a}$ and $\mathrm{b}$ ). Moreover, both aclidinium bromide $10^{-7} \mathrm{M}$ and AChE $10 \mathrm{U} \cdot \mathrm{mL}^{-1}$ were also able to suppress the CSE-induced collagen type I and $\alpha$-SMA mRNA and protein expression in human bronchial fibroblasts, which implicates a non-neuronal cholinergic system in the upregulation of myofibroblast markers (fig. 6a and b). To further study the role of this nonneuronal cholinergic system in the myofibroblast transformation, lung fibroblasts were incubated with the inhibitor of choline uptake transporter hemicholinium-3 at $50 \mu \mathrm{M}$ or with the AChE inhibitor neostigmine $10 \mu \mathrm{M}$ before CSE $2.5 \%$ exposure. Hemicholinium-3 significantly inhibited the CSEinduced collagen type I and $\alpha$-SMA mRNA and protein expression, while neostigmine significantly increased the CSE-induced collagen type I and $\alpha$-SMA mRNA and protein expression (fig. $6 \mathrm{c}$ and $\mathrm{d}$ ). In the absence of CSE, the different drugs assayed did not show any effect on mRNA or protein expression of collagen type I and $\alpha$-SMA (figs S3 and S4).

\section{CSE upregulation of myofibroblast markers is partially mediated by M1, M2 and M3 receptors}

Human bronchial fibroblasts transfected with siRNA for M1, M2 or M3 selectively suppressed specific muscarinic receptors without affecting other muscarinic receptors (fig. 7a and b). In this line, siRNA for all three muscarinic receptors showed suppression of CSE-induced myofibroblast markers collagen type I and $\alpha$-SMA (fig. 7c), indicating that all three muscarinic receptors may be involved in mediating the induction of the myofibroblast markers.

\section{DISCUSSION}

The main and novel results of this study are that: 1) CSE increased the myofibroblast markers collagen type I and $\alpha$-SMA in human bronchial fibroblast through a mechanism mediated by increase of intracellular ROS, depletion of cAMP and phosphorylation of ERK1/2; 2) CSE activated a non-neuronal cholinergic system by means of overexpression of ChAT, mediating increase of myofibroblast markers; and 3) the anticholinergic aclidinium bromide was able to attenuate the CSE-induced myofibroblast markers through inhibition of ROS generation, cAMP depletion, ERK1/2 phosphorylation and ChAT overexpression induced by CSE. These new findings provide in vitro evidence of the antiremodelling effect of aclidinium bromide on human bronchial fibroblasts in those cigarette smoke exposure situations that may contribute to the 

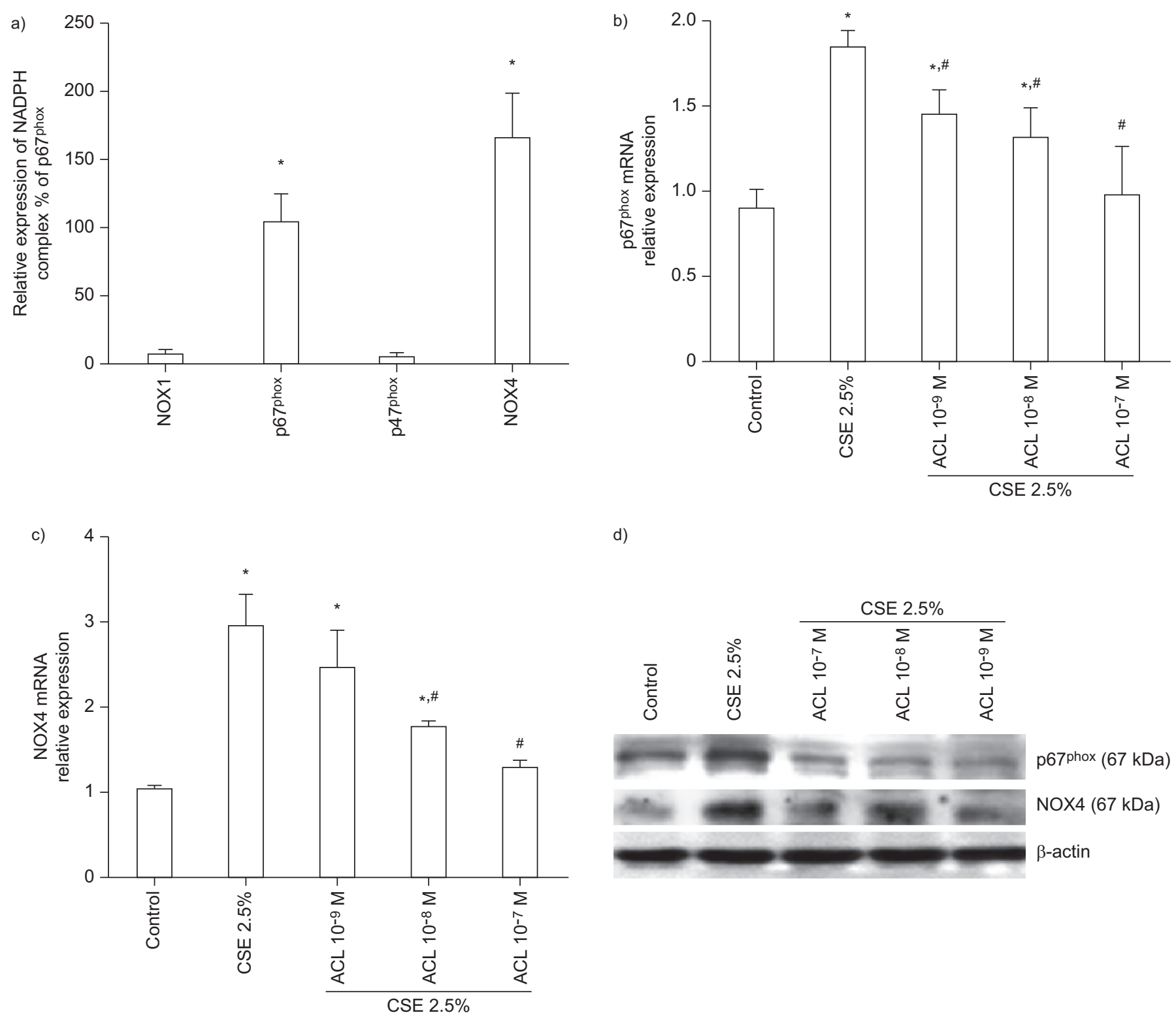

d)

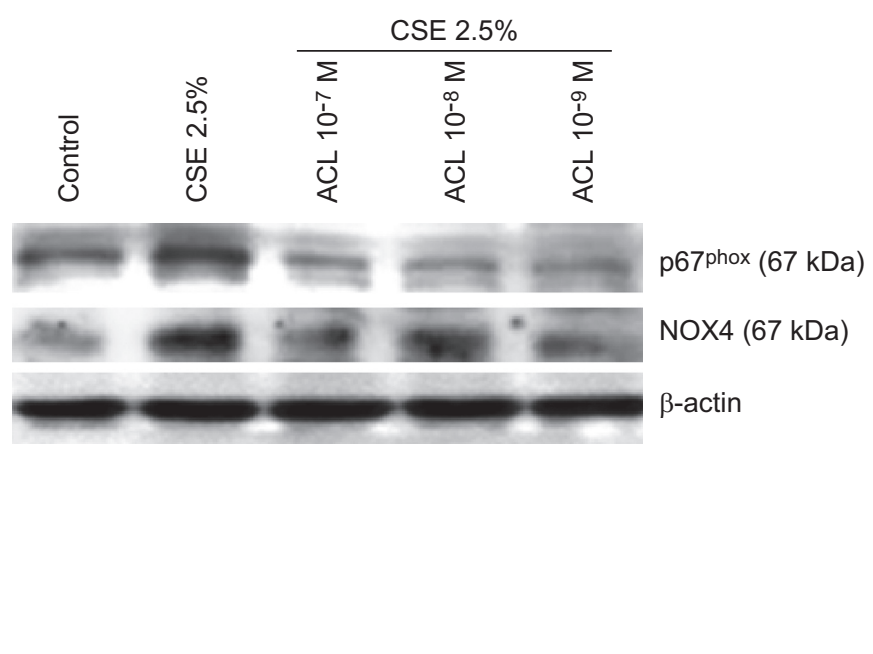

FIGURE 4. Aclidinium bromide (ACL) attenuated the cigarette smoke extract (CSE)-induced p67 ${ }^{\text {phox }}$ and NADPH oxidase (NOX) 4 upregulation in human bronchial fibroblasts. a) RNA was obtained from primary human bronchial fibroblasts and mRNA transcripts for NOX1, p67 $7^{\text {phox }}$, p4 $7^{\text {phox }}$ and NOX4 were quantified and normalised, setting $p 67^{\text {phox }}$ as $100 \%$. ACL dose-dependently attenuated the CSE $2.5 \%$-induced p $67^{\text {phox }}$ and NOX4 b, c) mRNA and d) protein upregulation following $24 \mathrm{~h}$ of stimulation. Results represent the mean \pm SEM of three independent experiments. a-c) One-way repeated-measures ANOVA $p<0.001$. *: $p<0.05$ with post hoc Bonferroni test compared with solvent controls; ${ }^{*}$ : $\mathrm{p}<0.05$ with post hoc Bonferroni test compared with stimulus.

amelioration of the peribronchiolar fibrosis observed in smokers with COPD.

It is known that airflow limitation in COPD patients occurs in distal airways considered as noncartilaginous conducting airways with an internal diameter $<2 \mathrm{~mm}$. In this work, we carefully dissected small bronchi of $\sim 2 \mathrm{~mm}$ to obtain bronchial fibroblasts, which may represent the place where peribronchiolar fibrosis occurs [17]. Bronchiolar fibroblast transformation into myofibroblasts is considered a key step in the process of increasing the thickness of the small airways, reducing airways radius and enhancing airflow limitation. Myofibroblasts share phenotypic characteristics with fibroblasts and airway smooth muscle cells. In this regard, myofibroblasts are characterised by the secretion of extracellular matrix components (e.g. collagen type I), a characteristic that is shared with fibroblasts but not with smooth muscle cells, and by formation of contractile apparatus (e.g. $\alpha$-SMA), a characteristic that is shared with airway smooth muscle cells but not with fibroblasts [3]. Therefore, we selected both of these molecular markers to analyse the myofibroblast-like phenotype. Several growth factors and pro-inflammatory mediators, such as transforming growth factor (TGF)- $\beta 1$, interleukin-13 and connective tissue growth factor, have been described as inducers of myofibroblast transition [18]; however, no data were available on cigarette smoke, the main risk factor for COPD. 
a)
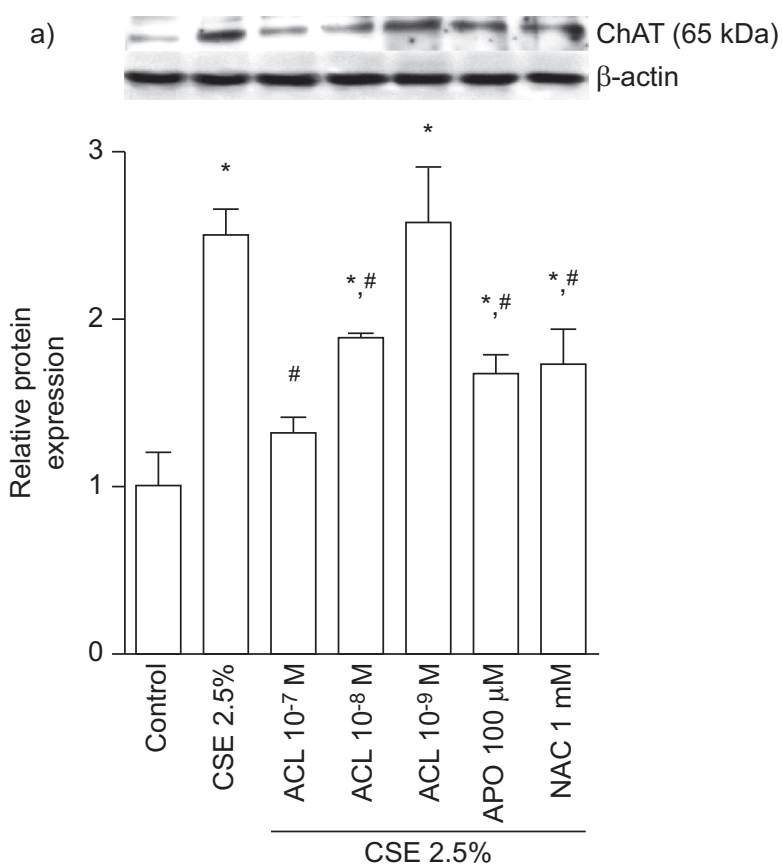

c)

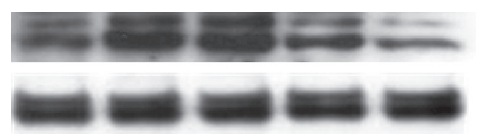

pERK1/2 (42-44 kDa)

$\operatorname{ERK} 1 / 2(42-44 \mathrm{kDa})$

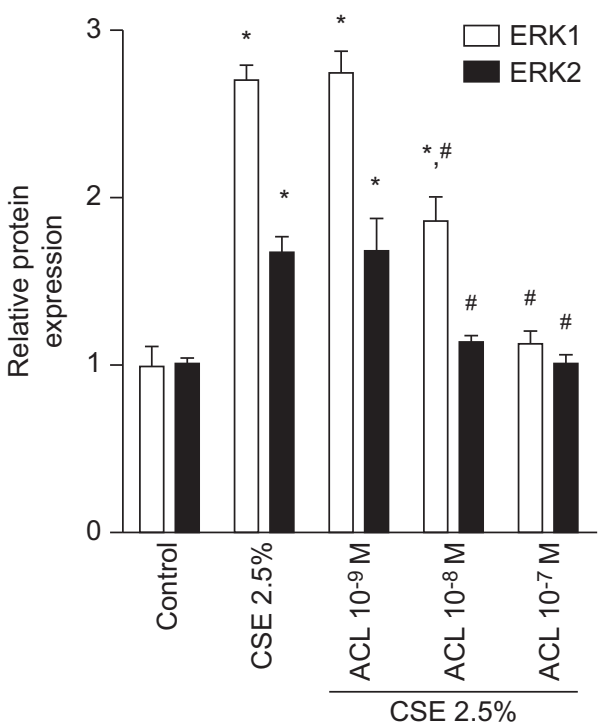

b)

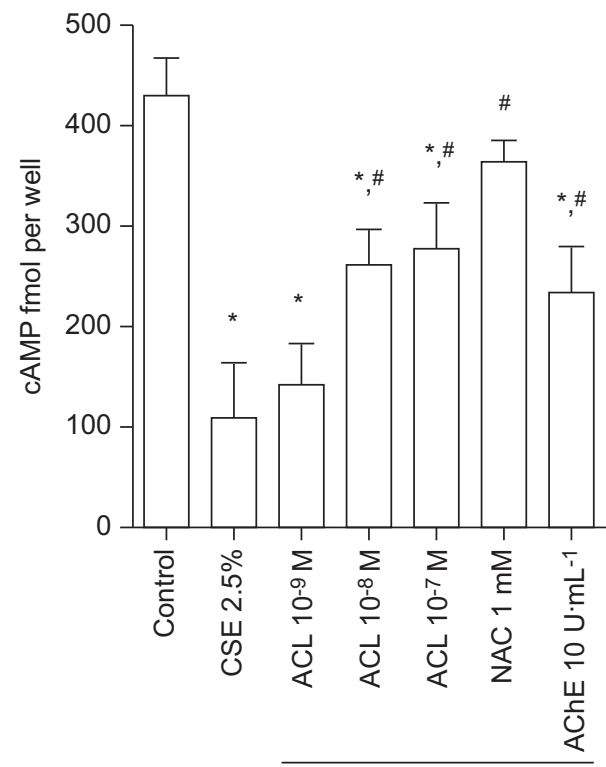

CSE $2.5 \%$

d)
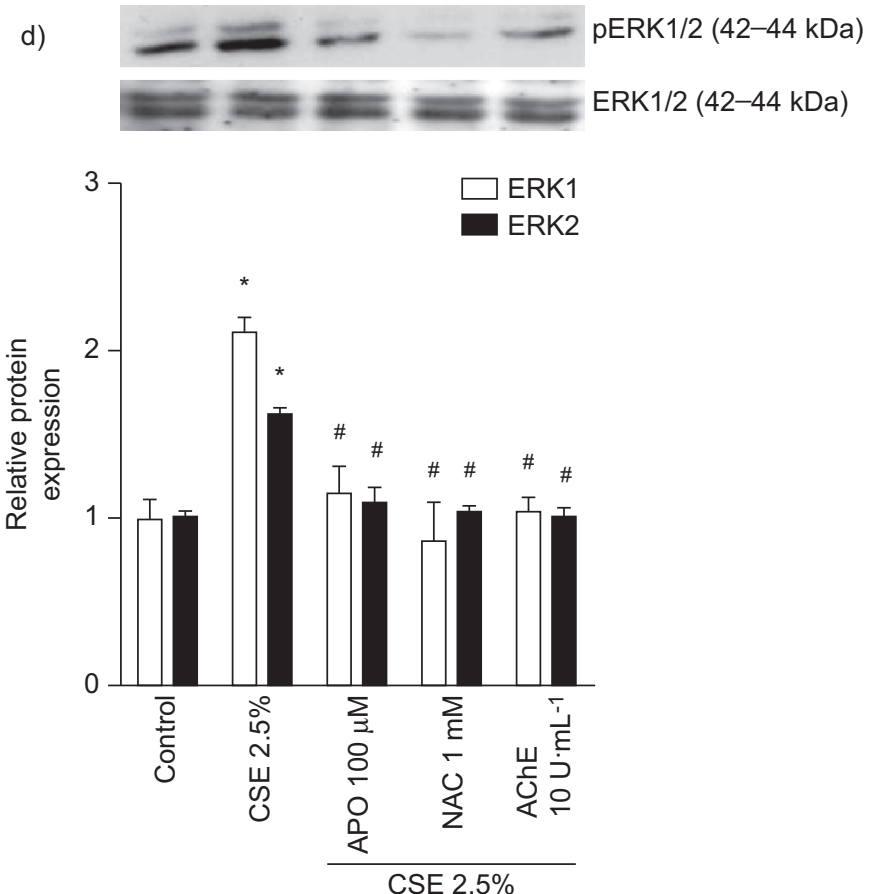

FIGURE 5. Cigarette smoke extract (CSE) activated a non-neuronal cholinergic system, decreased cyclic AMP (CAMP) and phosphorylated extracellular signal-regulated kinase (ERK)1/2. Human bronchial fibroblasts were pre-incubated for 30 min with a-C) aclidinium bromide (ACL; $\left.10^{-9}-10^{-7} \mathrm{M}\right), a, b$ and d) apocynin (APO; $\left.100 \mu \mathrm{M}\right), \mathrm{N}$ acetyl-L-cysteine (NAC; $1 \mathrm{mM}$ ) or b, d) acetylcholinesterase (AChE; $10 \mathrm{U} \cdot \mathrm{mL}^{-1}$ ) followed by the stimulation with CSE at $2.5 \%$ over $24 \mathrm{~h}$. a) Total protein was extracted and Western blots for choline acetyltransferase (ChAT) and $\beta$-actin, as an internal control, were performed. Representative Western blots are shown from three different experiments. b) Cells were lysed and intracellular cAMP was quantified using the cAMP Biotrak enzyme immunoassay system (Amersham, Cambridge, UK). c, d) Total protein was extracted and phosphorylated ERK1/2 (pERK1/2) and total ERK1/2 (as an internal control) protein expression were determined by Western blots. a, c, d) Densitometries of three different Western blots. Results represent the means \pm SEM of three to four independent experiments. One-way repeated-measures ANOVA $p<0.01$. *: $p<0.05$ with post hoc Bonferroni test compared with solvent controls; ${ }^{*}: \mathrm{p}<0.05$ with post hoc Bonferroni test compared with stimulus. 
a)

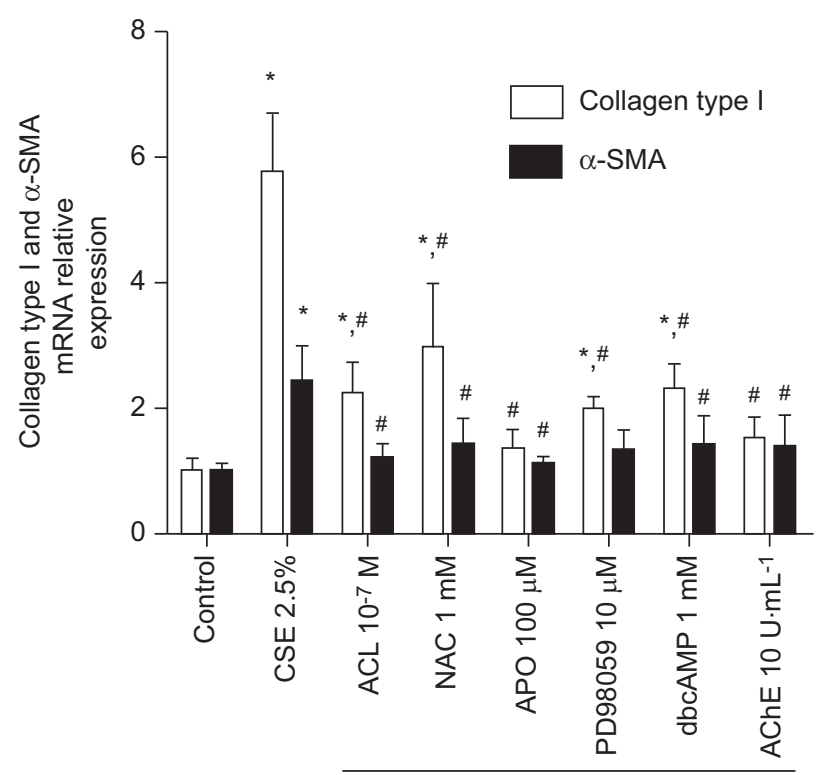

CSE $2.5 \%$

c)

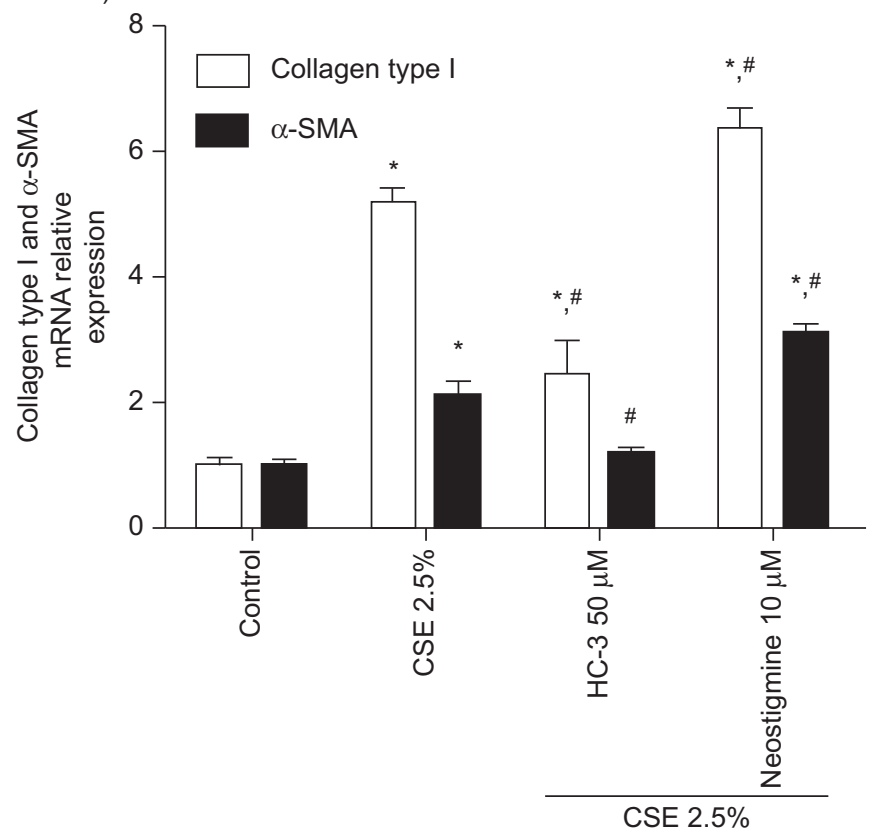

b)

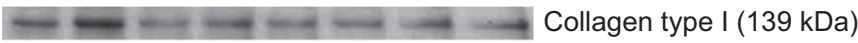
$-\omega-\ldots-\mathrm{SMA}(42 \mathrm{kDa})$

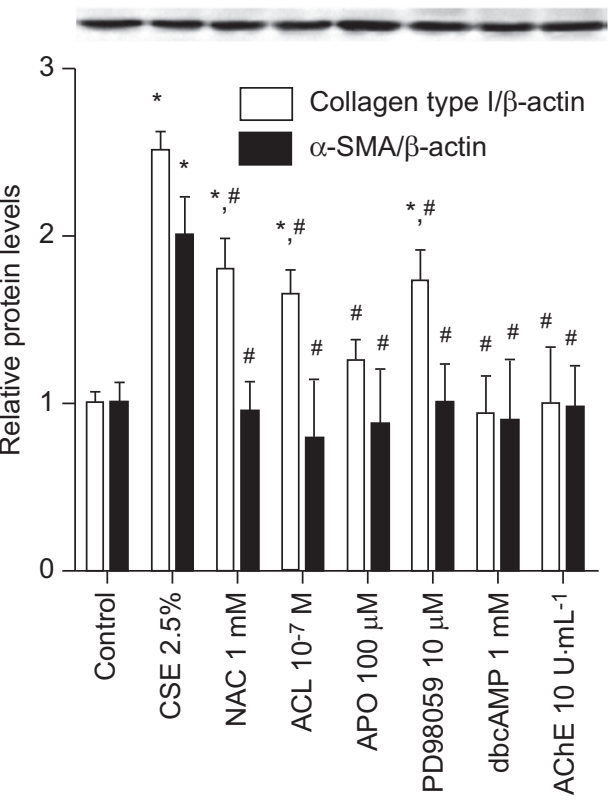

CSE $2.5 \%$

d)

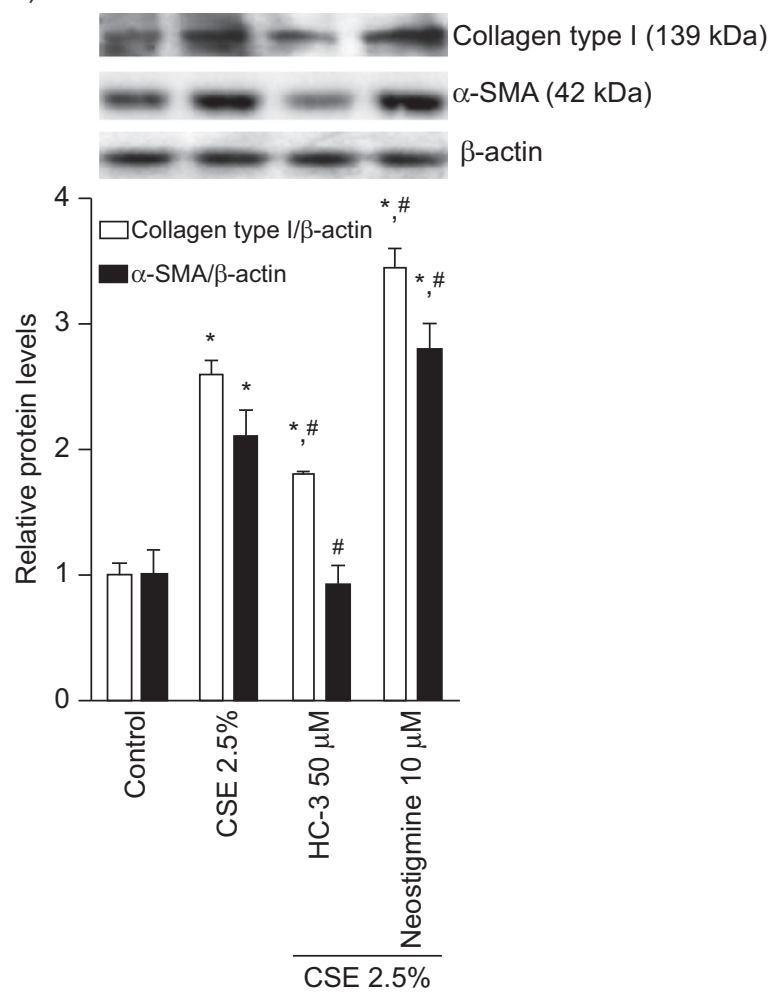

FIGURE 6. The cigarette smoke extract (CSE)-induced collagen type I and $\alpha$-smooth muscle actin ( $\alpha$-SMA) are partially mediated by a non-neuronal cholinergic pathway Human bronchial fibroblasts were pre-incubated for 30 min with aclidinium bromide (ACL; $10^{-7} \mathrm{M}$ ), apocynin (APO; $\left.100 \mu \mathrm{M}\right), \mathrm{N}$-acetyl-L-Cysteine (NAC; $1 \mathrm{mM}$ ), PD98059 (10 $\mu$ M), dibutyryl cyclic AMP (dbcAMP; $1 \mathrm{mM}$ ), acetylcholinesterase (AChE; $\left.10 \mathrm{U} \cdot \mathrm{mL}^{-1}\right)$, hemicholinium (HC)-3 (50 $\left.\mu \mathrm{M}\right)$ or neostigmine at $10 \mu \mathrm{M}$ followed by the stimulation with CSE at $2.5 \%$ over $24 \mathrm{~h}$. a , c) Total RNA or b, d) protein were extracted to quantify mRNA transcripts and protein expression of collagen type I and $\alpha$-SMA using appropriate primers and antibodies. a, c) Values of collagen type I and $\alpha$-SMA mRNA expression normalised to control group using glyceraldehyde phosphate dehydrogenase as an internal control. b, d) Densitometry of collagen type I or $\alpha$-SMA protein expression relative to $\beta$-actin and normalised to solvent controls. Representative Western blots of collagen type I and $\alpha$-SMA are shown. Each graph represents the mean \pm SEM of three to four independent experiments for Western blots and four for RNA experiments. a, b) One-way repeated-measures ANOVA $p<0.05$. *: $p<0.05$ with post hoc Bonferroni test compared with solvent controls; ${ }^{*}: p<0.05$ with post hoc Bonferroni test compared with stimulus. 


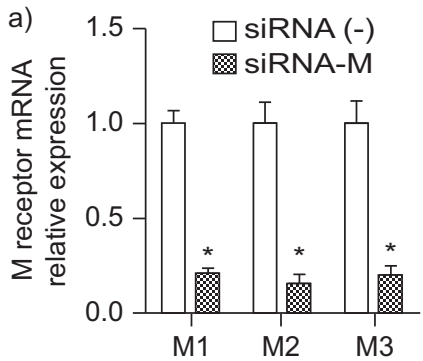

b)

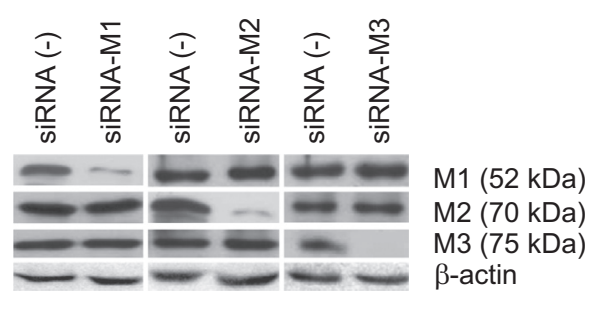

c)

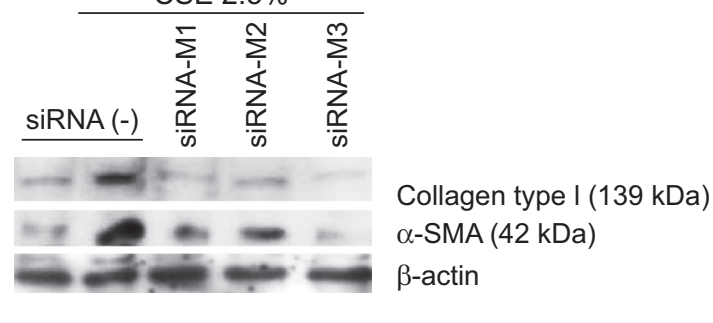

FIGURE 7. Cigarette smoke extract (CSE) increases myofibroblast markers by a non-neuronal cholinergic signalling mediated by muscarinic (M)1, M2 and M3 receptors. Human bronchial fibroblasts were selectively transfected with small interfering RNA (siRNA; $50 \mathrm{nM}$ ) for M1, M2 and M3 or with the negative control siRNA (-) for $48 \mathrm{~h}$ using Lipofectamine 2000 (Invitrogen, Paisley, UK) at final concentration of $2 \mu \mathrm{g} \cdot \mathrm{mL}^{-1}$. a, b) All siRNA targeting M1, M2 and M3 genes were able to reduce mRNA and protein expression for M1, M2 and M3 significantly without effecting other M receptors. $\beta$-actin was assayed as a positive control. Cells transfected with siRNA for M1, M2 and M3 genes attenuated the CSE $2.5 \%$-induced collagen type I and $\alpha$-smooth muscle actin ( $\alpha$-SMA) protein upregulation. Results are the mean \pm SEM of three independent experiments and are representative of three independent experiments per condition for Western blots. a) One-way repeated-measure ANOVA $p<0.001$. *: $p<0.05$ with post hoc Bonferroni test compared with siRNA (-) controls.

In this work, we prepared CSE as we and others have described previously [13, 14], which approximately corresponds to exposures associated with smoking slightly fewer than 0.5 packs per day to slightly fewer than 2 packs per day of cigarettes for CSE $2.5 \%$ and $10 \%$, respectively. Currently, several in vitro studies have been focused on effect of CSE on lung fibroblasts; however, no data are available on effect of CSE on bronchial fibroblast to myofibroblast transition. In this work, we observed that CSE promoted myofibroblast marker overexpression, which is compatible with the myofibroblast-like phenotype [3]. Furthermore, the CSE-induced expression of myofibroblast markers was mediated by intracellular ROS production, which was significantly increased after $2 \mathrm{~h}$ of exposure and persisted until at least $24 \mathrm{~h}$. The ROS increase preceded the collagen type I and $\alpha$-SMA overexpression (after $48 \mathrm{~h}$ ), suggesting a role of intracellular ROS as second messenger. A similar time-response of ROS production has previously been reported in human primary lung fibroblasts [19]. Intracellular ROS production in response to CSE is mediated by direct activation of the NADPH oxidase complex [20]. The NADPH oxidase complex is comprised several cytosolic and plasma membrane units, which vary depending on the cell type. Thus, in human lung fibroblasts, the NADPH oxidase components $\mathrm{p} 47^{\text {phox }}, \mathrm{p} 67^{\text {phox }}$, $\mathrm{p} 22^{\text {phox }}$ and NOX4 have been observed [21]. In this work, we found that the NADPH oxidase subunits $\mathrm{p} 67^{\text {phox }}$ and NOX4 were the most highly expressed in bronchial fibroblasts. The cytosolic $\mathrm{p} 67^{\text {phox }}$ subunit is mobilised under certain conditions to activate the plasma membrane plasmatic subunits NOX1, NOX2 or NOX3 to produce superoxide and/or hydrogen peroxide. In contrast, the plasma membrane unit NOX4 does not require interaction and activation by cytosolic regulatory subunits, so its activation is directly related to its expression [15]. In this regard, we found that CSE induced the upregulation of both $\mathrm{p} 67^{\text {phox }}$ and NOX 4 after $24 \mathrm{~h}$ of stimulation, which was in accordance with the increase of intracellular ROS.

Recent reports have related expression of NOX4 as a key factor of fibroblast progression and fibroblast-to-myofibroblast transition [22]. Therefore, a treatment diminishing NOX4 and, in turn, intracellular ROS, may prevent myofibroblast transition. We found that 24-h exposure to either the antioxidant NAC or the NADPH oxidase inhibitor apocynin inhibited the CSE-induced $\mathrm{p} 67^{\text {phox }}$ and NOX4 upregulation. These antioxidant modulators were also able to reduce myofibroblast markers induced by CSE, establishing a link between oxidative stress and myofibroblast transition. The anticholinergic aclidinium bromide attenuated myofibroblast markers induced by CSE and this action was mediated in part by the inhibition of the p67 $7^{\text {phox }}$ and NOX4 expression, as well as by the consequent reduction of intracellular ROS generated by CSE. These results suggest that CSE activates a nonneuronal cholinergic system. Previous reports have suggested that cigarette smoke may activate a non-neuronal cholinergic system in different cell types, including airways and human lung fibroblasts. For example, we have recently shown that CSE promotes synthesis and release of the mucin MUC5AC in differentiated bronchial epithelial cells by a mechanism mediated by release of acetylcholine, and can be inhibited by aclidinium bromide [8]. Furthermore, human lung fibroblasts from COPD patients have shown an increase of muscarinic receptors, as well as ChAT expression, an effect that was mimicked in healthy lung fibroblasts after CSE exposure [9]. In our experiments, AChE prevented the CSE-induced expression of myofibroblast markers, which is consistent with the presence of a non-neuronal cholinergic system. Other evidence to support the activation of a non-neuronal cholinergic system by cigarette smoke includes the upregulation of ChAT, the intracellular enzyme responsible of acetylcholine synthesis. We observed that CSE upregulated ChAT expression, which was prevented by the antioxidants NAC and apocynin, as well as by aclidinium bromide, suggesting the participation of intracellular ROS. Further evidence of the participation of non-neuronal cholinergic system was supported by the inhibition of myofibroblast transition blocking choline uptake with hemicholinium and increasing myofibroblast markers inhibiting AChE with neostigmine. 
Nowadays, it is believed that cigarette smoke contains $>6,000$ compounds and, possibly, this list will grow in line with the new analytical techniques available [23]. Taking into account this assertion, we know that CSE has the advantage of containing all of the compounds inhaled by smokers. However, due to the very complexity of CSE, it is difficult to identify the specific agent mediating a precise effect because of differences found for particular concentrations and durations of exposure of a given agent of CSE. To that end, one can perform a dose-response and time-course analysis and make some crude calculations to suggest that exposure mimics what might happen in vivo. Thus, for example, low concentrations of CSE $(<5 \%)$ have shown proliferative effects on lung fibroblasts [24-26], while higher $(>10 \%)$ concentrations showed inhibitory effects on lung fibroblast proliferation [27], thus indicating that among the $\sim 6,000$ substance of cigarette smoke, there are some proliferative and other anti-proliferative compounds that may act depending on their final balance.

In the present work, we have used $2.5 \%$ CSE, which is in agreement with the low doses of CSE demonstrating proliferative effects in previous studies [24-26], which support fibroblast activation in the process of myofibroblast transition [28].

Preliminary data from our laboratory indicated that CSE at $2.5 \%$ concentration had a slight increase of fibroblast proliferation after $48 \mathrm{~h}$ of exposure (based on a bromodeoxyuridine incorporation assay; data not shown). However, this increase was not enough to perform inhibitory experiments with aclidinium bromide. This was the main reason to discard these experiments, since the well-established myofibroblast markers collagen type I and $\alpha$-SMA are more reliable in mechanistic studies [3].

However, even if one could calculate exposure, experiments performed with CSE cannot mimic all of the components of the microenvironment that exist in living systems (e.g. cell-cell interactions). Thus, despite limitations, results from these studies allow determination of the capacity of CSE to influence cellular functions while eliminating other variables.

Intracellular cAMP is a second messenger that mediates a high number of anti-inflammatory processes. In addition to its antiinflammatory actions, cAMP also controls the inhibition of fibroblast activation, as well as the myofibroblast transition [29]. Thus, a decrease of the levels of cAMP could promote fibroblast to myofibroblast transition. This is evidenced by TGF- $\beta 1$, which increases the expression and activity of phosphodiesterases, the enzymes that degrade cAMP, promoting myofibroblast transition [30]. In the case of cigarette smoke, it has been shown that hydrogen peroxide, a component of tobacco smoke, swiftly elevates the activity of phosphodiesterase 4D3 attributed to phosphoinositide 3kinase and ERK-dependent phosphorylation [31]. In this respect, we have previously observed that CSE reduces intracellular cAMP levels in human differentiated bronchial epithelial cells by means of phosphodiesterase 4B upregulation (data not shown). In this work, we observed that CSE decreases intracellular levels of cAMP and that this effect was partially reversed by the antioxidant NAC and aclidinium bromide, suggesting a role of intracellular ROS. Furthermore,
AChE also attenuated the CSE-reduced cAMP, which indicates the involvement of the non-neuronal cholinergic system. This may be explained by the fact that the main muscarinic receptor expressed on lung fibroblasts is M2 [32], which is coupled to $G_{i}$ protein, so stimulation of M2 by means of a nonneuronal cholinergic system could also promote the inhibition of adenylate cyclase/cAMP pathway and, therefore, myofibroblast transition.

In line with our results, recently, it has been found that prostaglandin $(\mathrm{PG}) \mathrm{E}_{2}$, as a potent $\mathrm{CAMP}$ enhancer, may inhibit the activation of fibroblasts and their transformation into myofibroblasts [33, 34]. Thus, we cannot discount that one of the mechanisms of aclidinium bromide mediating the increase of cAMP and, consequently, the inhibition of myofibroblast transition could be the increase of $\mathrm{PGE}_{2}$ release.

Another pathway we investigated was ERK1/2 signalling. Previous studies have shown that ERK1/2 participates in fibroblast to myofibroblast transition [35] and that CSE directly phosphorylates ERK1/2 [9]. Thus, CSE-induced myofibroblast transition could be mediated in part by ERK1/2. In this work, we observed that CSE induced the phosphorylation of ERK1/2, which was reduced by aclidinium bromide and by the antioxidant treatment. Moreover, AChE also attenuates the CSE-induced ERK1/2 phosphorylation, suggesting that the activation of muscarinic receptors is also implicated. Previous results support the notion that muscarinic receptor activation increases collagen expression in human lung fibroblasts by means of ERK1/2 activation [12]. Therefore, a non-neuronal cholinergic system may also be participating in the process of CSE-induced ERK1/2 phosphorylation. Thus, the role of ERK1/2 in the CSE-induced myofibroblast markers was confirmed by the inhibitory effect of the ERK1/2 antagonist PD98059.

Based on these results, we may conclude that CSE activates muscarinic receptors in human bronchial fibroblasts by a nonneuronal cholinergic system, and that this mechanism is involved in the upregulation of the myofibroblasts markers. However, which isoform of muscarinic receptor plays a significant role in this mechanism is unclear. It has been shown that the inhibition of the $G_{i}$ protein with pertussis toxin reduces the fibroblast proliferation and collagen expression observed in response to muscarinic agonists [12], suggesting a key role for the M2 receptor. However, antagonists for M1, M2 and M3 were all effective at inhibiting the fibroblast proliferation induced by acetylcholine [9], although the specific muscarinic antagonists available are not fully selective [36]. To address this issue, we selectively silenced the M1, M2 and M3 genes using siRNA. Our results suggest that all M1, M2 and M3 receptors participate in CSE-induced expression of myofibroblast markers.

In summary, we have demonstrated that cigarette smoke, which is the main risk factor of COPD and participates in lung remodelling, may increase the expression of the myofibroblast markers collagen type I and $\alpha$-SMA through the activation of a non-neuronal cholinergic system, which is attenuated by the anticholinergic aclidinium bromide. Therefore, results observed in this work support that aclidinium bromide may play a role in regulating the peribronchiolar fibrotic remodelling of COPD in addition to the classical bronchodilator activity. 


\section{SUPPORT STATEMENT}

This work was supported by Almirall S.A. (Barcelona, Spain) and, in part, by grants SAF2011-26443 (to J. Cortijo), SAF2009-08913 (to E.J. Morcillo), FIS (Miguel Servet CP11/00293 (to J. Milara)), CIBERES (CB06/06/0027) and research grants from Regional Government (Prometeo/2008/045, "Generalitat Valenciana"; research grants from "Generalitat Valencia" AP-178/11 (to J. Milara)). T. Peiró received a research grant from Conselleria de Educacion, Generalitat Valenciana ACIF/2010/114. We thank C. Bryant from Complete Medical Communications (Macclesfield, UK) who provided copy-editing support funded by Almirall S.A.

\section{STATEMENT OF INTEREST}

Conflict of interest information can be found alongside the online version of this article at www.erj.ersjournals.com

\section{REFERENCES}

1 Hogg JC, Chu F, Utokaparch S, et al. The nature of small-airway obstruction in chronic obstructive pulmonary disease. $N$ Engl J Med 2004; 350: 2645-2653.

2 Jeffery PK. Remodeling and inflammation of bronchi in asthma and chronic obstructive pulmonary disease. Proc Am Thorac Soc 2004; 1: 176-183.

3 Singh SR, Hall IP. Airway myofibroblasts and their relationship with airway myocytes and fibroblasts. Proc Am Thorac Soc 2008; 5: 127-132.

4 Undem BJ, Kollarik M. The role of vagal afferent nerves in chronic obstructive pulmonary disease. Proc Am Thorac Soc 2005; 2: 355-360.

5 Gross NJ. Anticholinergic agents in asthma and COPD. Eur J Pharmacol 2006; 533: 36-39.

6 Bos IS, Gosens R, Zuidhof AB, et al. Inhibition of allergen-induced airway remodelling by tiotropium and budesonide: a comparison. Eur Respir J 2007; 30: 653-661.

7 Gosens R, Zaagsma J, Meurs H, et al. Muscarinic receptor signaling in the pathophysiology of asthma and COPD. Respir Res 2006; 7: 73.

8 Cortijo J, Mata M, Milara J, et al. Aclidinium inhibits cholinergic and tobacco smoke-induced MUC5AC in human airways. Eur Respir J 2011; 37: 244-254.

9 Profita M, Bonanno A, Siena L, et al. Smoke, choline acetyltransferase, muscarinic receptors, and fibroblast proliferation in chronic obstructive pulmonary disease. J Pharmacol Exp Ther 2009; 329: 753-763.

10 Prat M, Gavalda A, Fonquerna S, et al. Inhaled muscarinic antagonists for respiratory diseases: a review of patents and current developments (2006-2010). Expert Opin Ther Pat 2011; 21: 1543-1573.

11 Gavalda A, Miralpeix M, Ramos I, et al. Characterization of aclidinium bromide, a novel inhaled muscarinic antagonist, with long duration of action and a favorable pharmacological profile. J Pharmacol Exp Ther 2009; 331: 740-751.

12 Matthiesen S, Bahulayan A, Kempkens S, et al. Muscarinic receptors mediate stimulation of human lung fibroblast proliferation. Am J Respir Cell Mol Biol 2006; 35: 621-627.

13 Ortiz JL, Milara J, Juan G, et al. Direct effect of cigarette smoke on human pulmonary artery tension. Pulm Pharmacol Ther 2010; 23: 222-228.

14 Su Y, Han W, Giraldo C, et al. Effect of cigarette smoke extract on nitric oxide synthase in pulmonary artery endothelial cells. Am J Respir Cell Mol Biol 1998; 19: 819-825.

15 Petry A, Weitnauer M, Gorlach A. Receptor activation of NADPH oxidases. Antioxid Redox Signal 2010; 13: 467-487.

16 Huang S, Wettlaufer SH, Hogaboam C, et al. Prostaglandin $E_{2}$ inhibits collagen expression and proliferation in patient-derived normal lung fibroblasts via E prostanoid 2 receptor and cAMP signaling. Am J Physiol Lung Cell Mol Physiol 2007; 292: L405-L413.

17 Burgel PR, Bourdin A, Chanez P, et al. Update on the roles of distal airways in COPD. Eur Respir Rev 2011; 20: 7-22.

18 Scotton CJ, Chambers RC. Molecular targets in pulmonary fibrosis: the myofibroblast in focus. Chest 2007; 132: 1311-1321.

19 Baglole CJ, Bushinsky SM, Garcia TM, et al. Differential induction of apoptosis by cigarette smoke extract in primary human lung fibroblast strains: implications for emphysema. Am J Physiol Lung Cell Mol Physiol 2006; 291: L19-L29.

20 Dasari V, Gallup M, Lemjabbar H, et al. Epithelial-mesenchymal transition in lung cancer: is tobacco the "smoking gun"? Am J Respir Cell Mol Biol 2006; 35: 3-9.

21 Dhaunsi GS, Paintlia MK, Kaur J, et al. NADPH oxidase in human lung fibroblasts. J Biomed Sci 2004; 11: 617-622.

22 Hecker L, Vittal R, Jones T, et al. NADPH oxidase-4 mediates myofibroblast activation and fibrogenic responses to lung injury. Nat Med 2009; 15: 1077-1081.

23 Milara J, Cortijo J. Tobacco, Inflammation, and Respiratory Tract Cancer. Curr Pharm Des 2012; 18: 3901-3938.

24 Krimmer DI, Burgess JK, Wooi TK, et al. Matrix proteins from smoke-exposed fibroblasts are pro-proliferative. Am J Respir Cell Mol Biol 2012; 46: 34-39.

25 Liu Y, Gao W, Zhang D. Effects of cigarette smoke extract on A549 cells and human lung fibroblasts treated with transforming growth factor- $\beta 1$ in a coculture system. Clin Exp Med 2010; 10: 159-167.

26 Wang Q, Fan J, Liu S. [Effects of cigarette smoke solution and chrysotile on proliferation activity of human embryo lung cells]. Zhonghua Yu Fang Yi Xue Za Zhi 1999; 33: 231-233.

27 Miglino N, Roth M, Lardinois D, et al. Cigarette smoke inhibits lung fibroblast proliferation by translational mechanisms. Eur Respir J 2012; 39: 705-711.

28 Milara J, Serrano A, Peiro T, et al. Aclidinium inhibits human lung fibroblast to myofibroblast transition. Thorax 2012; 67: 229-237.

29 Huang SK, Wettlaufer SH, Chung J, et al. Prostaglandin $E_{2}$ inhibits specific lung fibroblast functions via selective actions of PKA and Epac-1. Am J Respir Cell Mol Biol 2008; 39: 482-489.

30 Kolosionek E, Savai R, Ghofrani HA, et al. Expression and activity of phosphodiesterase isoforms during epithelial mesenchymal transition: the role of phosphodiesterase 4. Mol Biol Cell 2009; 20: 4751-4765.

31 Hill EV, Sheppard CL, Cheung YF, et al. Oxidative stress employs phosphatidyl inositol 3-kinase and ERK signalling pathways to activate cAMP phosphodiesterase-4D3 (PDE4D3) through multisite phosphorylation at Ser239 and Ser579. Cell Signal 2006; 18: 2056-2069.

32 Racke K, Haag S, Bahulayan A, et al. Pulmonary fibroblasts, an emerging target for anti-obstructive drugs. Naunyn Schmiedebergs Arch Pharmacol 2008; 378: 193-201.

33 Kolodsick JE, Peters-Golden M, Larios J, et al. Prostaglandin $\mathrm{E}_{2}$ inhibits fibroblast to myofibroblast transition via $\mathrm{E}$ prostanoid receptor 2 signaling and cyclic adenosine monophosphate elevation. Am J Respir Cell Mol Biol 2003; 29: 537-544.

34 Thomas PE, Peters-Golden M, White ES, et al. $\mathrm{PGE}_{2}$ inhibition of TGF- $\beta 1$-induced myofibroblast differentiation is Smad-independent but involves cell shape and adhesion-dependent signaling. Am J Physiol Lung Cell Mol Physiol 2007; 293: L417-L428.

35 Caraci F, Gili E, Calafiore M, et al. TGF- $\beta 1$ targets the GSK-3 $\beta / \beta$ catenin pathway via ERK activation in the transition of human lung fibroblasts into myofibroblasts. Pharmacol Res 2008; 57: 274-282.

36 Caulfield MP, Birdsall NJ. International Union of Pharmacology. XVII. Classification of muscarinic acetylcholine receptors. Pharmacol Rev 1998; 50: 279-290. 